\title{
SURVEY OF LUNGWORM INFECTION OF DOMESTIC CATS IN HUNGARY
}

\author{
Sára KISZELY ${ }^{1}$, Mónika GYURKOVSZKY ${ }^{1}$, Norbert SOLYMOSI ${ }^{2}$ and Róbert FARKAS ${ }^{1 *}$ \\ ${ }^{1}$ Department of Parasitology and Zoology and ${ }^{2}$ Centre for Bioinformatics, \\ University of Veterinary Medicine, István u. 2, H-1078 Budapest, Hungary
}

(Received 15 May 2019; accepted 31 July 2019)

\begin{abstract}
From 61 settlements of 12 Hungarian counties, 303 domestic cats were included in this survey. Between autumn 2016 and spring 2018, fresh faecal samples were randomly collected and examined by flotation and by the BaermannWetzel method for the presence of lungworm infection. No eggs of Eucoleus aerophilus were detected. Morphological identification of first instar larvae (L1) was also carried out. In the faeces of 60 cats (19.8\%) from 17 settlements and Budapest, L1 of Aelurostrongylus abstrusus were found. More than half of the cats were from the western part of the country. The average number of larvae per gram of faeces was $190.2 \pm 304.88$. These results are in line with the former findings on the prevalence of aelurostrongylosis of domestic cats in Hungary. In addition, Oslerus rostratus was also found for the first time in the faecal samples of three cats from the eastern part of the country, infected also with Ae. abstrusus. The average age $(2.51 \pm 1.26$ years $)$ of infected cats indicates that lungworm infection is more common among younger cats. No relationship was found between the lungworm infection and the sex of cats. Non-neutered cats had a significantly higher proportion of lungworm infections. Two-thirds of the infected cats were apparently healthy, and only 19 individuals showed clinical signs of respiratory disorders.
\end{abstract}

Key words: Lungworms, Aelurostrongylus abstrusus, Oslerus rostratus, cat, survey, Hungary

Lungworm infection of domestic and wild cats occurs in many countries around the world. It is most commonly caused by Aelurostrongylus abstrusus, Railliet, 1898 (Strongylida, Angiostrongylidae), called the cat lungworm (Anderson, 2000; Bowman, 2000). The 5- to 10-mm-long adults reside in the alveolar duct and the terminal bronchioles of the lungs. Over the past decade, other lungworm species of domestic cats such as Troglostrongylus brevior and T. subcrenatus (Strongylida, Crenosomatidae), Oslerus rostratus (syn. Anafilaroides rostratus) (Strongylida, Filaroididae) and Eucoleus aerophilus (syn. Capillaria aerophila) (Enoplida, Trichuridae) have also been reported (Traversa et al., 2009; Jefferies et al., 2010; Brianti et al., 2012, 2014b; Di Cesare et al., 2014; Giannelli

\footnotetext{
*Corresponding author; E-mail: farkas.robert@univet.hu; Phone: 0036 (01) 478-4188
} 
et al., 2017). There have been several cases when two or more lungworm species occurred concurrently in cats (Juste et al., 1992; Jefferies et al., 2010; Traversa et al, 2014; Daikou et al., 2015; Varcasia et al., 2015). With the exception of $E$. aerophilus, the other species develop indirectly with gastropod intermediate hosts. Cats can be infected by intermediate hosts or various other animals (e.g. small mammals, lizards, frogs) which consumed slugs and snails acting as paratenic hosts (Anderson, 2000; Bowman, 2000; Pennisi et al., 2015). Depending on the parasite species, the degree of infection and the immunological status of the host, the parasitosis can be asymptomatic or the cats may show mild to severe clinical signs (coughing, sneezing, tachypnoea). Heavy infection can even be fatal (Traversa et al., 2010; Traversa and Di Cesare, 2013; Philbey et al., 2014; Pennisi et al., 2015).

Data on the distribution and prevalence of cat lungworm infection in Hungary are scarce. In a postmortem examination of 57 stray cats originating from 9 hunting areas of the country $C$. aerophila worms were found in 14 cadavers (Takács and Takács, 2002), Ae abstrusus was detected by autopsy (Kávai, 1977; Dobos-Kovács, 1981; Takács and Takács, 2002) or faecal examination (Capári et al., 2013).

The objectives of this investigation were to enhance the knowledge on the distribution and risk factors of lungworm infection of domestic cats in Hungary.

\section{Materials and methods}

\section{Sampling}

Altogether 303 cats from 61 settlements of 12 counties (Table 1 and Fig. 1) were randomly included in the survey. Most cats $(n=269)$ had owners, while the remainder were kept in temporary accommodation. Between autumn 2016 and spring 2018 fresh faecal samples were collected once. Sampling was done with the owners' permission and assistance.

The approx. 5-gram samples per cat stored in plastic jars having individual numbers were usually taken to the laboratory on the same day or 2-3 days later after storing them in a fridge. Simultaneously, a questionnaire was completed for each cat (e.g. breed, age, sex, keeping, presence/absence of respiratory signs, last anthelmintic treatment).

\section{Test method}

The E. aerophilus eggs were examined by the flotation method using zinc sulphate solution. The lungworm larvae (L1) were isolated by Baermann-Wetzel method (Giannelli et al., 2015). One gram of faecal sample packed in a $10 \times 10 \mathrm{~cm}$ double-layered gauze was kept in a glass filled with lukewarm water for $24 \mathrm{~h}$. 
Table 1

The number of cats sampled per site (N), the number (N) of cats infected with Aelurostrongylus abstrusus and Oslerus rostratus and the number of infected cats with respiratory signs (e.g. frequent sneezing, running nose)

\begin{tabular}{|c|c|c|c|c|}
\hline Site & $\mathrm{N}$ & Ae. abstrusus $(\mathrm{N})$ & O. rostratus $(\mathrm{N})$ & Respiratory signs $(\mathrm{N})$ \\
\hline Alsózsolca & 1 & 0 & 0 & 0 \\
\hline Badacsonytomaj & 1 & 1 & 0 & 1 \\
\hline Balatonalmádi & 5 & 0 & 0 & 0 \\
\hline Bedő & 6 & 6 & 0 & 4 \\
\hline Békés & 3 & 0 & 0 & 0 \\
\hline Békéscsaba & 7 & 0 & 0 & 0 \\
\hline Böcs & 2 & 0 & 0 & 0 \\
\hline Budaörs & 3 & 1 & 0 & 0 \\
\hline Budapest & 40 & 1 & 0 & 0 \\
\hline Csatár & 2 & 0 & 0 & 0 \\
\hline Csopak & 4 & 0 & 0 & 0 \\
\hline Debrecen & 13 & 0 & 0 & 0 \\
\hline Debrecen-Józsa & 3 & 1 & 0 & 1 \\
\hline Diósd & 1 & 0 & 0 & 0 \\
\hline Dömsöd & 5 & 0 & 0 & 0 \\
\hline Dunakeszi & 2 & 0 & 0 & 0 \\
\hline Érd & 13 & 2 & 0 & 0 \\
\hline Erdőbénye & 4 & 0 & 0 & 0 \\
\hline Gesztely & 3 & 0 & 0 & 0 \\
\hline Gödöllö & 4 & 0 & 0 & 0 \\
\hline Gyula & 3 & 0 & 0 & 0 \\
\hline Hajdúböszörmény & 17 & 2 & 2 & 0 \\
\hline Hajdúdorog & 9 & 0 & 0 & 0 \\
\hline Hajdúszoboszló & 1 & 0 & 0 & 0 \\
\hline Herceghalom & 1 & 0 & 0 & 0 \\
\hline Hernádkak & 6 & 0 & 0 & 0 \\
\hline Hernádkak-Belegrád & 9 & 7 & 1 & 6 \\
\hline Hernádnémeti & 2 & 0 & 0 & 0 \\
\hline Hódmezővásárhely & 4 & 0 & 0 & 0 \\
\hline Ikrény & 1 & 0 & 0 & 0 \\
\hline Iváncsa & 1 & 1 & 0 & 0 \\
\hline Kazincbarcika & 2 & 0 & 0 & 0 \\
\hline Kistarcsa & 1 & 0 & 0 & 0 \\
\hline Komárom & 1 & 0 & 0 & 0 \\
\hline Köröshegy & 3 & 0 & 0 & 0 \\
\hline Mezőberény & 2 & 0 & 0 & 0 \\
\hline Miskolc & 8 & 3 & 0 & 1 \\
\hline Nyíregyháza & 6 & 0 & 0 & 0 \\
\hline Óhíd & 15 & 13 & 0 & 0 \\
\hline Okány & 1 & 0 & 0 & 0 \\
\hline Orosháza & 3 & 0 & 0 & 0 \\
\hline Sárospatak & 6 & 0 & 0 & 0 \\
\hline Sátoraljaújhely & 4 & 0 & 0 & 0 \\
\hline Sümeg & 7 & 6 & 0 & 3 \\
\hline Sümegcsehi & 2 & 2 & 0 & 0 \\
\hline Szeged & 10 & 0 & 0 & 0 \\
\hline Szentendre & 3 & 0 & 0 & 0 \\
\hline Szentimrefalva & 8 & 6 & 0 & 2 \\
\hline Tolcsva & 2 & 0 & 0 & 0 \\
\hline Tura & 1 & 0 & 0 & 0 \\
\hline Ukk & 4 & 4 & 0 & 1 \\
\hline Vác & 7 & 0 & 0 & 0 \\
\hline Vámosszabadi & 1 & 0 & 0 & 0 \\
\hline Vésztő & 4 & 1 & 0 & 0 \\
\hline Vilmány & 3 & 0 & 0 & 0 \\
\hline Zalaegerszeg & 10 & 0 & 0 & 0 \\
\hline Zalagyömörő & 2 & 2 & 0 & 0 \\
\hline Zalaszegvár & 1 & 1 & 0 & 0 \\
\hline Zalaszentiván & 4 & 0 & 0 & 0 \\
\hline Zalaszentlőrinc & 2 & 0 & 0 & 0 \\
\hline Zamárdi & 4 & 0 & 0 & 0 \\
\hline
\end{tabular}


After $5 \mathrm{~min}$ of centrifugation of the liquid at $600 \mathrm{rpm}$, the morphological identification of larvae found in the sediment was carried out based on the published descriptions (Traversa and Di Cesare, 2016). The body length and the morphology of head and tail end were considered (Table 2). The identification of $O$. rostratus L1 was confirmed with PCR by Alessio Giannelli in Bari, Italy (personal information). The number of larvae per one gram of faeces (LPG) was determined.

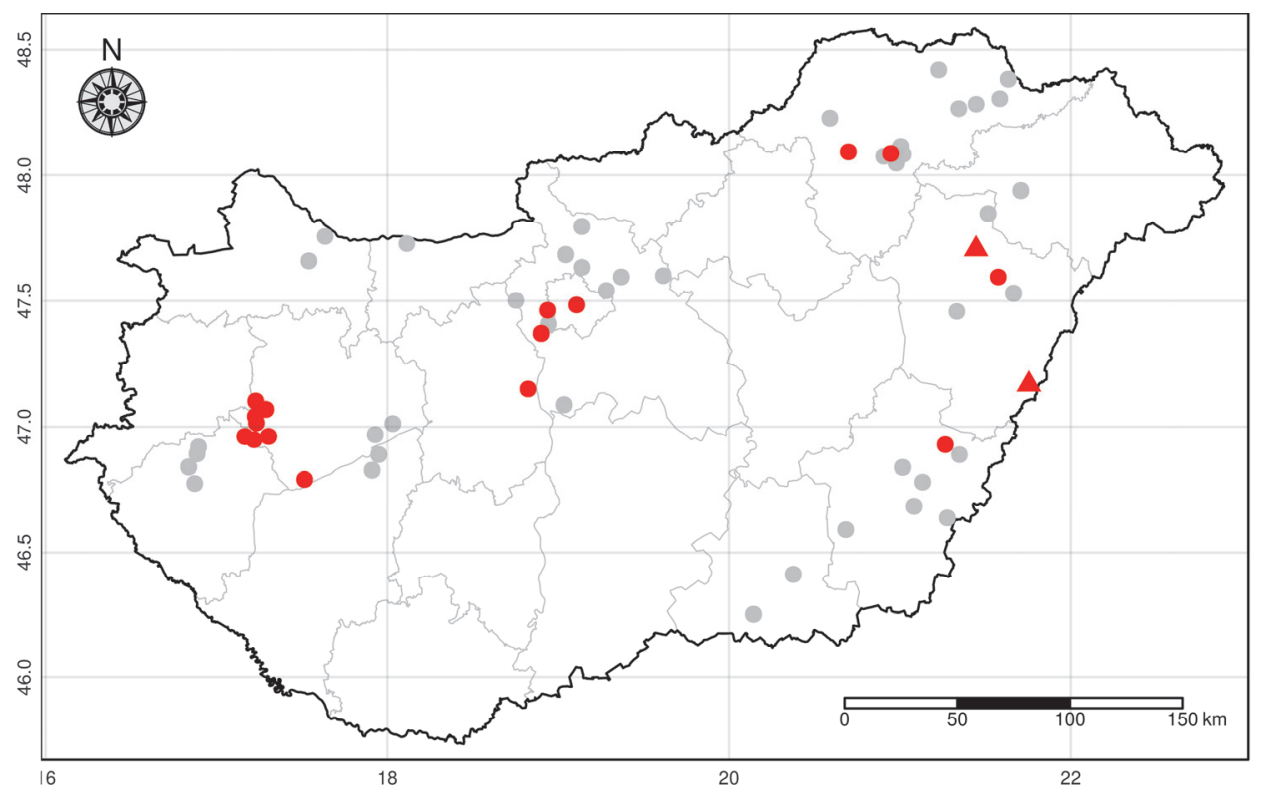

Fig. 1. Negative sampling sites (grey dots), sites of Aelurostrongylus abstrusus (red dots) and cats dually infected with Ae. abstrusus and Oslerus rostratus (red triangles)

\section{Statistical evaluation}

The independence of infection from age group, sex, and keeping mode was analysed by Fisher's exact test. We used propensity score-based pairing to form sample pairs (Dinya and Solymosi, 2016). A limit value of $\mathrm{P}<0.05$ was used to evaluate the results. All analyses were performed in R environment ( $\mathrm{R}$ Core Team, 2019).

\section{Results}

No E. aerophilus eggs occurred in the samples.

There were Ae. abstrusus L1 in the faeces of 60 cats (19.8\%; 95\% CI: $15.71-$ 24.65) living in 17 settlements and one kept in Budapest (Table 1 and Fig. 1). The LPG values showed significant differences, with an average number of $190.2 \pm$ 
304.9. Oslerus rostratus L1 were also found in the faecal samples of three cats infected with Ae. abstrusus. All infected cats belonged to the European shorthaired breed, most of them (47/60, 78.33\%; 95\% CI: 66.38-86.87) lived outdoors, and 11 (18.33\%; 95\% CI: 10.56-29.92) stayed both indoors and outdoors. Only two out of 74 animals kept indoors had lungworm larvae in their samples (2.7\% 95\% CI: $0.74-9.33)$. Significantly more animals which lived outdoors or both indoors and outdoors were infected than those kept exclusively indoors (OR: $12.15,95 \%$ CI: $3.07-105.49, \mathrm{P}<0.001$ ). The average age of the infected cats was $2.51 \pm 1.26$ years, the youngest and the oldest was 8 months and 6 years old, respectively. There was no significant difference $(\mathrm{P}=0.5916)$ between the infection rate of cats younger than one year of age and 1- to 5-year-old cats. The animals under one year and between 1 and 5 years old had a higher risk of lungworm infection than cats older than 5 years (OR: 7.85, 95\% CI: 1.93-69.17, P < 0.001 and OR: $6.16,95 \% \mathrm{CI}: 1.24-60.20, \mathrm{P}=0.0157)$. The proportion of infected males (34/178, 19.1\%, 95\% CI: $14.0-25.5)$ and females $(26 / 125,20.8 \%, 95 \%$ CI: 14.61-28.73) did not differ significantly. A significantly higher proportion of non-neutered cats were infected with lungworms (OR: 2.98, 95\%CI: 1.49-6.32, $\mathrm{P}<0.001)$. When propensity score-based matching was applied, in order to have a balanced population $(\mathrm{n}=120)$ for free range and neutering, the effect of young age remained (OR: $3.83,95 \% \mathrm{CI}: 1.09-17.22, \mathrm{P}=0.034$ ). Nearly one-third of the infected animals (19/60, 31.67\%, 95\% CI: 21.31-44.23) showed respiratory signs (e.g. frequent sneezing, running nose) but their number did not differ significantly $(P>0.05)$ from those of infected cats not showing clinical signs.

\section{Discussion}

The results of this study are in line with previous findings showing that Ae. abstrusus infection of domestic cats is fairly prevalent in Hungary (Kávai, 1977; Dobos-Kovács, 1981; Takács and Takács, 2002; Capári et al., 2013). The occurrence of aelurostrongylosis in new regions can be considered a new finding. In this survey the prevalence of this parasitosis was $19.8 \%$. In the previous pathological or faecal examinations a lower rate of infections was detected: Ae. abstrusus worms were found only in 2 out of 50 cats (4\%) (Kávai, 1977) and in one out of 57 stray cats (1.7\%) (Takács and Takács, 2002) at autopsy. In a parasitological survey of 235 domestic cats carried out in the western part of Hungary, the prevalence of aelurostrongylosis was $14.5 \%$ (Capári et al., 2013). In the present study, more than half of the infected animals $(n=35 / 60,58.3 \%)$ lived in that region. Further studies could answer the question whether the endemic occurrence of this parasitosis in that region is related to environmental and weather conditions more favourable for the intermediate hosts, which are also assumed in other parasitic infections (Patz et al., 2000; Morgan et al., 2009). Lungworm in- 
fections of cats mostly caused by Ae. abstrusus have been found in several European countries where different prevalence values were reported, e.g. Italy: 8.117.8\% (Traversa et al., 2008; Di Cesare et al., 2015; Giannelli et al., 2015, 2017), Portugal: 6.25-17.4\% (Payo-Puente et al., 2008; Waap et al., 2014; Giannelli et al., 2017), Spain: 1.7-5\% (Miró et al., 2004; Giannelli et al., 2017); Denmark: 8.86-13.6\% (Olsen et al., 2015; Hansen et al., 2017). By examining more faecal samples collected during 2-3 consecutive days, it may have been possible to find a higher prevalence of lungworm infection than obtained in our study, as the intermittent discharge of larvae was observed in chronically infected cats (Ribeiro and Lima, 2001; Payo-Puente et al., 2008). Recent European studies have reported that at least one of 10 cats is exposed to lungworm infections, the incidence of this parasitosis being more common on the continent than previously thought. In this context, it was noted that lungworm infection of cats is not regarded as a growing threat because there are no previous data to be used for comparison (Giannelli et al., 2017). The authors assumed that the lower occurrence of infected cats found in the western part of Europe can be explained by the more frequent application of anthelmintic drugs.

\section{Table 2}

Morphometric features of first-stage larvae of Aelurostrongylus abstrusus, Troglostrongylus brevior, T. subcrenatus and Oslerus rostratus

\begin{tabular}{|c|c|c|c|}
\hline Species & Length $(\mu \mathrm{m})$ & Head & Tail \\
\hline Aelurostrongylus abstrusus & $360-410$ & $\begin{array}{l}\text { rounded, terminal } \\
\text { oral opening }\end{array}$ & $\begin{array}{l}\text { kinked (S shaped), } \\
\text { distinct knob-like or } \\
\text { small finger-like } \\
\text { projections }\end{array}$ \\
\hline Troglostrongylus brevior & $300-360$ & $\begin{array}{l}\text { pointed, subterminal } \\
\text { oral opening }\end{array}$ & $\begin{array}{l}\text { gradually tapered } \\
\text { to the extremity, } \\
\text { deep dorsal and } \\
\text { a shallower } \\
\text { ventral incisure }\end{array}$ \\
\hline Troglostrongylus subcrenatus & $270-300$ & $\begin{array}{l}\text { pointed, subterminal } \\
\text { oral opening }\end{array}$ & $\begin{array}{l}\text { gradually tapered } \\
\text { to the extremity, } \\
\text { deep dorsal and } \\
\text { a shallower } \\
\text { ventral incisure }\end{array}$ \\
\hline Oslerus rostratus & $330-410$ & $\begin{array}{l}\text { central oral opening, } \\
\text { surrounded by a } \\
\text { cuticular ring with } \\
\text { dorsal and ventral } \\
\text { prominences }\end{array}$ & $\begin{array}{l}\text { with a constriction } \\
\text { anterior to the end } \\
\text { and tip with } \\
\text { a kinked appearance }\end{array}$ \\
\hline
\end{tabular}


This is a first record for Hungary that in the present study $O$. rostratus was also found in three cats (in the form of co-infection with Ae. abstrusus). The 30to 40-mm-long adults of $O$. rostratus were mostly found in the bronchial submucosa and peribronchial tissues of wild cats and lynx (Brianti et al., 2014a). Since the first description of this nematode species (Gerichter, 1949), it has also been found in domestic cats of some European countries, which may have been infected accidentally (Juste et al., 1992; Millán and Casanova, 2009; Brianti et al., 2014a; Varcasia et al., 2015; Giannelli et al., 2017). Further studies could reveal how three cats kept in two settlements in the eastern part of the country became infected. One of the possible reasons for the rare occurrence of $O$. rostratus in domestic cats is that the living space of wild cats is narrowing, and their number is constantly decreasing in the country (Biró et al., 2009). Except for two infected cats the third one lived outdoors or both indoors and outdoors. A similar result has been reported by others, suggesting that the living conditions have a decisive influence on the infection of animals, since the consumption of naturally infected intermediate or paratenic hosts are necessary for lungworm infections (Genchi et al., 2014; Giannelli et al., 2017). The two cats that were living indoors had probably become infected before they were switched to indoor keeping.

The average age of infected cats $(2.51 \pm 1.26$ years $)$ indicates that lungworm infection is more common among younger cats. Examining the infection rate of 303 animals divided into three age groups, there was a significantly lower risk of infection among animals above 5 years of age due to the acquired immunity (Pennisi et al., 2015). In other studies, there was no difference between the infection rates of the different age groups (Genchi et al., 2014; Tamponi et al., 2014). Some authors have reported that there is a higher risk of infection among young animals (Traversa et al., 2010; Barutzki and Schaper, 2013; Di Cesare et al., 2013). According to other authors, lungworms are more common among adult cats (Mircean et al., 2010; Knaus et al., 2014). We agree with those researchers who say that cats can be infected with lungworms at any age if they can reach the infective intermediate or paratenic hosts in the environment (Beugnet et al., 2014; Giannelli et al., 2015).

No relationship was found between lungworm infection and the sex of animals, as the parasitosis occurred in almost the same proportion in males and females, as opposed to other findings (Traversa et al., 2008; Tamponi et al., 2014). We agree with Traversa et al. (2008) and Genchi et al. (2014) who reported that the sex of cats did not affect their infection rate. Non-neutered cats had a significantly higher proportion of lungworm infections, which is probably due to a decrease in their activity after the spaying operation.

Two-thirds of the infected cats were free of clinical signs, and only 19 showed respiratory signs. Italian researchers reported that more than $50 \%$ of animals infected with Ae. abstrusus had clinical signs (Traversa et al., 2008; Genchi et al., 2014; Di Cesare et al., 2015). The question arises whether or not there 
is a correlation between LPG values and the occurrence of clinical signs. Contradictory data have been reported so far. There were scientists who did not find that LPG values were significantly higher in cats with clinical signs (Traversa and Di Cesare, 2016). Others have reported that the development of clinical signs results from the massive egg production of worms and the lesions produced in the lungs mainly by L1. Therefore, higher levels of LPG are found in such individuals (Naylor et al., 1984; Gerdin et al., 2011; Genchi et al., 2014).

The knowledge regarding lungworm infection of domestic cats living in Hungary has been expanded with the results of the current studies. However, the following questions have arisen, which need to be answered by further studies: What is the frequency of the parasitosis caused by $O$. rostratus in domestic cats? Do Troglostrongylus spp. occur in the country? What are the most common intermediate hosts of the nationwide distributed Ae. abstrusus? Can the geographical distribution of cat lungworms be influenced by the climate change in the country?

\section{Acknowledgements}

We wish to thank the veterinarians involved in this study for their kind collaboration and all pet owners who consented to their pets' involvement. This research was supported partly by the 17896-4/2018/FEKUTSTRAT grant of the Hungarian Ministry of Human Capacities.

\section{References}

Anderson, R. C. (2000): The superfamily Metastrongyloidea. In: Anderson, R. C. (ed.) Nematode Parasites of Vertebrates. Their Development and Transmission. CABI, Wallingford, UK. pp. 129-229.

Barutzki, D. and Schaper, R. (2013): Occurrence and regional distribution of Aelurostrongylus abstrusus in cats in Germany. Parasitol. Res. 112, 855-861.

Beugnet, F., Bourdeau, P., Chalvet-Monfray, K., Cozma, V., Farkas, R., Guillot, J., Halos, L., Joachim, A., Losson, B., Miró, G., Otranto, D., Renaud, M. and Rinaldi, L. (2014): Parasites of domestic owned cats in Europe: co-infestations and risk factors. Parasit. Vectors 7, 291.

Biró, Zs., Szemethy, L. and Heltai, M. (2009): The wild cat: tribulations of an endangered predator 1. Current status and sources of risk [in Hungarian]. Vadászkutya [Hunting Dog] 3, 50-52.

Bowman, D. D. (2000): Respiratory system parasites of the dog and cat. Part I. Nasal mucosa and sinuses, and respiratory parenchyma. In: Bowman, D. D. (ed.) Companion and Exotic Animal Parasitology. International Veterinary Information Service (www.ivis.org).

Brianti, E., Gaglio, G., Giannetto, S., Annoscia, G., Latrofa, M. S., Dantas-Torres, F., Traversa, D. and Otranto, D. (2012): Troglostrongylus brevior and Troglostrongylus subcrenatus (Strongylida: Crenosomatidae) as agents of broncho-pulmonary infestation in domestic cats. Parasit. Vectors 5, 178.

Brianti, E., Gaglio, G., Napoli, E., Falsone, L., Giannelli, A., Annoscia, G., Varcasia, A., Giannetto, S., Mazzullo, G. and Otranto, D. (2014a): Feline lungworm Oslerus rostratus (Strongylida: Filaridae) in Italy: first case report and histopathological findings. Parasitol. Res. 113, 3853-3857. 
Brianti, E., Giannetto, S., Dantas-Torres, F. and Otranto, D. (2014b): Lungworms of the genus Troglostrongylus (Strongylida: Crenosomatidae): Neglected parasites for domestic cats. Review. Vet. Parasitol. 202, 104-112.

Capári, B., Hamel, D., Visser, M., Winter, R., Pfister, K. and Rehbein, S. (2013): Parasitic infections of domestic cats, Felis catus, in western Hungary. Vet. Parasitol. 192, 33-42.

Daikou, A., Di Cesare, A., Barros, L. A., Morelli, S., Halos, L., Beugnet, F. and Traversa, D. (2015): Occurrence of Aelurostrongylus abstrusus and Troglostrongylus brevior in domestic cats in Greece. Parasit. Vectors 8, 590.

Di Cesare, A., Frangipane di Regalbono, A., Tessarin, C., Seghetti, M., Iorio, R., Simonato, G. and Traversa, D. (2014): Mixed infection by Aelurostrongylus abstrusus and Troglostrongylus brevior in kittens from the same litter in Italy. Parasitol. Res. 113, 613-618.

Di Cesare, A., Veronesi, F., Grillotti, E., Manzocchi, S., Perrucci, S., Beraldo, P., Cazzin, S., De Liberato, C., Barros, L. A., Simonato, G. and Traversa, D. (2015): Respiratory nematodes in cat populations of Italy. Parasitol. Res. 114, 4463-4469.

Di Cesare, A., Crisi, P. E., Di Giulio, E., Veronesi, F., Frangipane di Regalbono, A., Talone, T. and Traversa, D. (2013): Larval development of the feline lungworm Aelurostrongylus abstrusus in Helixaspersa. Parasitol. Res. 112, 3101-3108.

Dinya, E. and Solymosi, N. (2016): Biometrics in Clinics 2. Solving Tasks in R Environment [in Hungarian]. Medicina, Budapest, ISBN 9789632265742.

Dobos-Kovács, M. (1981): On the pathological alterations of lungworm infestation of cats caused by Aelurostrongylus abstrusus [in Hungarian, with English abstract]. Magy. Allatorvosok 36, 552-556.

Genchi, M., Ferrari, N., Fonti, P., De Francesco, I., Piazza, C. and Viglietti, A. (2014): Relation between Aelurostrongylus abstrusus larvae excretion, respiratory and radiographic signs in naturally infected cats. Vet. Parasitol. 206, 182-187.

Gerdin, J. A., Slater, M. R., Makolinski, K. V., Looney, A. L., Appel, L. D., Martin, N. M. and McDonough, S. P. (2011): Post-mortem findings in 54 cases of anesthetic-associated death in cats from two spay-neuter programs in New York State. J. Feline Med. Surg. 13, 959-966.

Gerichter, C. B. (1949): Studies on the nematodes parasitic in the lungs of Felidae in Palestine. Parasitol. 39, 251-262.

Giannelli, A., Brianti, E., Varcasia, A., Colella, V., Tamponi, C., Di Paola, G., Knaus, M., Halos, L., Beugnet, F. and Otranto, D. (2015): Efficacy of Broadline ${ }^{\circledR}$ spot-on against Aelurostrongylus abstrusus and Troglostrongylus brevior lungworms in naturally infected cats from Italy. Vet. Parasitol. 209, 273-277.

Giannelli, A., Capelli, G., Joachim, A., Hinney, B., Losson, B., Kirkova, Z., René-Martellet, M., Papadopoulos, E., Farkas, R., Napoli, E., Brianti, E., Tamponi, C., Varcasia, A., Alho, A. M., Madeira De Carvalho, L., Cardoso, L., Maia, C., Mircean, V., Mihalca, A. D., Miró, G., Schnyder, M., Cantacessi, C., Colella, V., Cavalera, M. A., Latrofa, M., S., Annoscia, G., Knaus, M., Halos, L., Beugnet, F. and Otranto, D. (2017): Lungworms and gastrointestinal parasites of domestic cats: a European perspective. Int. J. Parasitol. 47, 517-528.

Hansen, A. P., Skarbye, L. K., Vinther, L. M., Willesen, J. L., Pipper, C. B., Olsen, C. S. and Mejer, H. (2017): Occurrence and clinical significance of Aelurostrongylus abstrusus and another endoparasites in Danish cats. Vet. Parasitol. 234, 31-39.

Jefferies, R., Vrhovec, M. G., Wallner, N. and Catalan, D. R. (2010): Aelurostrongylus abstrusus and Troglostrongylus sp. (Nematoda: Metastrongyloidea) infections in cats inhabiting Ibiza, Spain. Vet. Parasitol. 173, 344-348.

Juste, R. A., Garcia, A. L. and Mencía, L. (1992): Mixed infestation of a domestic cat by Aelurostrongylus abstrusus and Oslerus rostratus. Angew. Parasitol. 33, 56-60.

Kávai, A. (1977): To the knowledge of helminth parasites of cats in Hungary [in Hungarian]. Parasit. Hung. 10, 91-93. 
Knaus, M., Rapti, D., Shukullari, E., Kusi, I., Postoli, R., Xhaxhiu, D., Silaghi, C., Hamel, D., Visser, M., Winter, R. and Rehbein, S. (2014): Characterisation of ecto- and endoparasites in domestic cats from Tirana, Albania. Parasitol. Res. 113, 3361-3371.

Millán, J. and Casanova, J. C. (2009): High prevalence of helminth parasites in feral cats in Majorca Island (Spain). Parasit. Res. 106, 183-188.

Mircean, V., Titilincu, A. and Vasile, C. (2010): Prevalence of endoparasites in household cat ( $\mathrm{Fe}$ lis catus) populations from Transylvania (Romania) and association with risk factors. Vet. Parasitol. 171, 163-166.

Miró, G., Montoya, A., Jiménez, S., Frisuelos, C., Mateo, M. and Fuentes, I. (2004): Prevalence of antibodies to Toxoplasma gondii and intestinal parasites in stray, farm and household cats in Spain. Vet. Parasitol. 126, 249-255.

Morgan, E. R., Jefferies, R., Krajewski, M., Ward, P. and Shaw, S. E. (2009): Canine pulmonary angiostrongylosis: The influence of climate on parasite distribution. Parasitol. Int. 58, 406-410.

Naylor, J. R., Hamilton, J. M. and Weatherley, A. J. (1984): Changes in the ultra-structure of feline pulmonary arteries following infection with the lungworm Aelurostrongylus abstrusus. Br. Vet. J. 140, 181-190.

Olsen, C. S., Willesen, J. L., Pipper, C. B. and Mejer, H. (2015): Occurrence of Aelurostrongylus abstrusus (Railliet, 1898) in Danish cats: A modified lung digestion method for isolating adult worms. Vet. Parasitol. 210, 32-39.

Patz, J. A., Graczyk, T. K., Geller, N. and Vittor, A. Y. (2000): Effects of environmental change on emerging parasitic diseases. Int. J. Parasitol. 30, 1395-1405.

Payo-Puente, P., Botelho-Dinis, M., Urueña, A. M. C., Payo-Puente, M., Gonzalo-Orden, J. M. and Rojo-Vazquez, F. A. (2008): Prevalence study of the lungworm Aelurostrongylus abstrusus in stray cats of Portugal. J. Feline Med. Surg. 10, 242-246.

Pennisi, M. G., Hartmann, K., Addie, D. D., Boucraut-Baralon, C., Egberink, H., Frymus, T., Gruffydd-Jones, T., Horzinek, M. C., Hosie, M. J., Lloret, A., Lutz, H., Marsilio, F., Radford, A. D., Thiry, E., Truyen, U. and Möstl, K. (2015): Lungworm disease in cats. ABCD guidelines on prevention and management. J. Feline Med. Surg. 17, 626-636.

Philbey, A. W., Krause, S. and Jefferies, R. (2014): Verminous pneumonia and enteritis due to hyperinfection with Aelurostrongylus abstrusus in a kitten. J. Comp. Path. 150, 357-360.

R Core Team (2019): A language and environment for statistical computing. R Foundation for Statistical Computing, Vienna, Austria. URL https://www.R-project.org/.

Ribeiro, V. M. and Lima, W. S. (2001): Larval production of cats infected and re-infected with $A e-$ lurostrongylus abstrusus (Nematoda: Protostrongylidae). Rev. Méd. Vét. 152, 815-820.

Takács, A. and Takács, P. (2002): Data on worm infestation of domestic cats (Felis catus) in Hungarian hunting areas [in Hungarian, with English abstract]. Magy Allatorvosok 124, 26-30.

Tamponi, C., Varcasia, A., Brianti, E., Pipia, A. P., Frau, V., Pinna Parpaglia, M. L., Sanna, G., Garippa, G., Otranto, D. and Scala, A. (2014): New insights on metastrongyloid lungworms infecting cats of Sardinia, Italy. Vet. Parasitol. 203, 222-226.

Traversa, D. and Di Cesare, A. (2013): Feline lungworms: what a dilemma. Trends Parasitol. 29, 423-430.

Traversa, D. and Di Cesare, A. (2016): Diagnosis and management of lungworm infections in cats. Cornerstones, dilemmas and new avenues. Review. J. Feline Med. Surg. 18, 7-20.

Traversa, D., Di Cesare, A. and Conboy, G. (2010): Canine and feline cardiopulmonary parasitic nematodes in Europe: emerging and underestimated. Parasit. Vectors 23, 62.

Traversa, D., Di Cesare, A., Milillo, P., Iorio, R. and Otranto, D. (2009): Infection by Eucoleus aerophilus in dogs and cats: Is another extra-intestinal parasitic nematode of pets emerging in Italy? Res. Vet. Sci. 87, 270-272.

Traversa, D., Lia, R. P., Iorio, R., Boari, A., Paradies, P., Capelli, G., Avolio, S. and Otranto, D. (2008): Diagnosis and risk factors of Aelurostrongylus abstrusus (Nematoda, Strongylida) infection in cats from Italy. Vet. Parasit. 153, 182-186. 
Traversa, D., Romanucci, M., Di Cesare, A., Malatesta, D., Cassini, R., Iorio, R., Seghetti, M. and Salda, L. D. (2014): Gross and histopathological changes associated with Aelurostrongylus abstrusus and Troglostrongylus brevior in a kitten. Vet. Parasitol. 201, 158-162.

Varcasia, A., Brianti, E., Tamponi, C., Pipia, A. P., Cabras, P. A., Mereu, M., Dantas-Torres, F., Scala, A. and Otranto, D. (2015): Simultaneous infection by four feline lungworm species and implications for the diagnosis. Parasitol. Res. 114, 317-321.

Waap, H., Gomes, J. and Nunes, T. (2014): Parasite communities in stray cat populations from Lisbon, Portugal. J. Helminthol. 88, 389-395.

This is an open-access article distributed under the terms of the Creative Commons Attribution 4.0 International License (https://creativecommons.org/licenses/by/4.0/), which permits unrestricted use, distribution, and reproduction in any medium, provided the original author and source are credited, a link to the CC License is provided, and changes - if any - are indicated. (SID_1) 